\section{Kidney \\ Blood Pressure Research}

Kidney Blood Press Res 2014;39:581-590

DOI: $10.1159 / 000368471$

Published oniıne: vecember 15, 2014

Accepted: November 14, 2014

(C) 2014 S. Karger AG, Basel

www.karger.com/kbr

1423-0143/14/0396-0581\$39.50/0

This is an Open Access article licensed under the terms of the Creative Commons AttributionNonCommercial 3.0 Unported license (CC BY-NC) (www.karger.com/OA-license), applicable to the online version of the article only. Distribution permitted for non-commercial purposes only.

\title{
Effects of Paricalcitol and Aliskiren Combination Therapy on Experimental Diabetic Nephropathy Model in Rats
}

\author{
Zehra Eren $^{a} \quad$ Mehmet Yalçin Günal $^{b} \quad$ Elif Arı Bakirg Jale Coban ${ }^{c}$ \\ Berrak Çağlayan $^{b} \quad$ Nur Ekimcib ${ }^{b}$ Sinem Ethemoglu ${ }^{b}$ Ozgur Albayrak ${ }^{d}$ \\ Tuba Akdeniz ${ }^{e} \quad$ Gülderen Yanikkaya Demirel ${ }^{f} \quad$ Ertuğrul Kiliç $^{b} \quad$ Gülçin Kantarcia
}

aDepartment of Nephrology, Yeditepe University; ${ }^{b}$ Department of Physiology, Medipol University, School of Medicine; 'Department of Biochemistry; ${ }^{\mathrm{d} D e p a r t m e n t ~ o f ~ B i o c t e c h n o l o g y ; ~}{ }^{\mathrm{e} D e p a r t m e n t}$ of Molecular Medicine; ${ }^{f}$ Department of Immunology, Yeditepe University; 9 Department of Nephrology, Kartal Research and Training Hospital, Istanbul, Turkey

\section{Key Words}

Aliskiren • Diabetic nephropathy • Paricalcitol

\begin{abstract}
Background/Aims: The aim of the present study was to investigate the effect of combination of aliskiren with paricalcitol on experimental diabetic nephropathy (DN) model in rats. Methods: Forty male Sprague Dawley rats were divided into 5 groups of 8 rats each, namely the control (Group C), diabetes (Group D), aliskiren (Group A), paricalcitol (Group P), and aliskiren plus paricalcitol (Group $A+P$ ) groups. Aliskiren was given by oral-gavage at a dose of $50 \mathrm{mg} / \mathrm{kg} /$ day once daily for 12 weeks. Paricalcitol was given by intraperitoneally at a dose of $0,4 \mu \mathrm{g} / \mathrm{kg} /$ three day of week for 12 weeks. Renal function parameters, oxidative stress biomarkers, mRNA expression of renin-angiotensin system parameters and kidney histology were determined. Results: Group $A+P$ had lower mean albümin-to-creatinine ratio (ACR) $(p=0.004)$ as well as higher creatinine clearance $(C C r)(p<0.005)$ than the diabetic rats (Group D). Combination therapy significantly increased $C C r$ (Group A+P vs Group A, $p<0.005$; Group $A+P$ vs Group $P, p=0.022$ ) and reduced ACR (Group $A+P$ vs Group A, $p=0.018$; Group A+P vs Group $P, p<0.005)$ when compared to monotherapy. Serum malondialdehyde levels were significantly lower $(p=0.004)$; glutathion levels $(p=0.003)$, glutathion peroxidase $(p=0.004)$ and superoxide dismutase $(p<0.005)$ activities were significantly higher in group $A+P$ than in group D. The mean scores of mRNA expression of renin $(p<0.005)$, angiotensin II $(p=0.012)$ and angiotensin type 1 receptor $(p=0.018)$ in group $A+P$ were significantly lower. Although combination therapy showed no additional effect on oxidative system, renin-angiotensin system and renal histology, aliskiren plus paricalcitol significantly decreased interstitial fibrosis volume when compared to monotherapy (Group A+P vs Group A, $p<0.005$; Group A+P vs
\end{abstract}




\section{Kidney \\ Blood Pressure Research}

Group $\mathrm{P}, \mathrm{p}=0.002$ ). Conclusion: Our data seem to suggest a potential role of aliskiren plus paricalcitol acting synergystically for reducing the progression of diabetic nephropathy in an experimental rat model.

Copyright $\odot 2014$ S. Karger AG, Basel

\section{Introduction}

Diabetic nephropathy (DN), a severe microvascular complication frequently associated with both type 1 and type 2 diabetes mellitus, is a leading cause of renal failure [1]. The condition can also lead to accelerated cardiovascular disease and macrovascular complications. Currently available therapies have not been fully efficacious in the treatment of DN, suggesting that further understanding of the molecular mechanisms underlying the pathogenesis of DN is necessary for the improved management of this disease [2].

The renin-angiotensin-aldosterone system (RAAS) plays an essential role in the development of diabetic nephropathy, and blockage of the RAAS is currently used for treatment $[3,4]$. The major problem of RAAS blockage, including both angiotensin-converting enzyme inhibitors (ACEs) and angiotensin receptor blockers (ARBs), is the disruption of the negative feedback inhibition of renin production lead into compensatory renin increase.

Aliskiren - 2(S),4(S),5(S),7(S)-N-(2-carbamoyl-2-methylpropyl)-5-amino-4-hydroxy2,7-diisopropyl-8-[4-methoxy-3-(3-methoxypropoxy)phenyl]-octanamide hemifumarate is a direct renin inhibitor that has been approved for lowering arterial blood pressure [5, 6]. Inhibition of renin, a rate-limiting step in Angiotensin II production, represents the target for inhibition of the RAAS and may be a new option for reducing the progression of DN.

Paricalcitol (19-nor-1,25-dihydroxyvitamin D2) is an active, non-hypercalcemic vitamin $\mathrm{D}$ analogue that shows biological activity similar to vitamin $\mathrm{D}$, but has fewer adverse effects [7]. In addition to its primary role in calcium metabolism and bone mineralization, vitamin D and its non-hypercalcemic analogue paricalcitol have pleiotropic and antioxidant effects on cellular homeostasis [8]. Studies in experimental nephropathy models have demonstrated that paricalcitol improves glomerular damage and tubular toxicity $[9,10]$. VITAL study reported that addition of paricalcitol to RAAS inhibition lowers albuminuria in patients with DN [11]. Recently it has been shown that paricalcitol has antioxidant effects on the myocardium [12] and supresses the RAAS in the kidney [13].

The aim of the present study was to investigate the effect of combination of aliskiren with paricalcitol on experimental DN model in rats. The finding that vitamin $\mathrm{D}$ is a potent negative endocrine regulator of the RAAS, we hypothesised that combination therapy could reduce the progression more than individual effect of aliskiren and paricalcitol. We evaluated renal function parameters, serum levels and activities of oxidative stress biomarkers, expression of RAAS components on renal tissue, and renal histology after treatment with aliskiren and paricalcitol in combination.

\section{Materials and Methods}

\section{Animals}

All animal procedures adhered to the guidelines of European Council for animal care and the Animal Ethics Review Committee of Yeditepe University (Istanbul, Turkey) approved the experimental protocol. Male Sprague Dawley rats, weighing 240-260 g, reared at the Yeditepe University Animal Research Center were used in the study. The rats were housed at the Experimental Animal Center in a controlled environment at a temperature of $22 \pm 1{ }^{\circ} \mathrm{C}$ with a 12 -hour light/dark cycle. The animals were fed distilled water ad libitum and standart chow diet. Individual metabolic cages were used for the collection of $24 \mathrm{~h}$ urine. 


\section{Kidney \\ Blood Pressure Research}

\begin{tabular}{l|l}
\hline Kidney Blood Press Res 2014;39:581-590 \\
\hline DOI: $10.1159 / 000368471$ & $\begin{array}{l}\text { C } 2014 \text { S. Karger AG, Basel } \\
\text { www.karger.com/kbr }\end{array}$ \\
\hline Publisned onlIne: December 15, 2014 &
\end{tabular}

Eren et al.: Aliskiren and Paricalcitol on Experimental Diabetic Nephropathy Model

\section{Experimental design}

Diabetes was induced after an over night fast by a single intraperitoneal injection (ip) of $65 \mathrm{mg} / \mathrm{kg}$ streptozotocin (STZ) (SigmaAldrichCo.,St Louis, MO,USA) freshly dissolved in 10mM citrate buffer (pH 4.2). Blood glucose levels were measured $48 \mathrm{~h}$ after STZ with Optium Exceed test strip glucometer (Abbott, IL, USA) using one drop of tail blood. Rats with a blood glucose level over $300 \mathrm{mg} / \mathrm{dl}$ were considered as diabetic. Diabetic rats received daily 1 to 8 IU Insulin Detemir (Levemir, NovoNordisc, Bagsvaerd, Denmark) to prevent weight loss and ketotic state. Blood glucose levels were monitoring weekly to determine insulin dosage. Three weeks after induction of diabetes, rats were randomly assigned to one of the following five groups:

(1) Diabetic nephropathy group (Group D) (n=8): Rats treated only with Insulin to maintain blood glucose levels approximately $300 \mathrm{mg} / \mathrm{dl}$,

(2) Aliskiren group (Group A) (n=8): Rats recieved Aliskiren (Raziles, Novartis, Switzerland) 10 mg/ $\mathrm{kg} /$ day dosage by oral gavage and insülin to maintain blood glucose levels app. $300 \mathrm{mg} / \mathrm{dl}$,

(3) Paricalcitol group (Group P) (n=8): Rats treated with intraperitoneal (ip) paricalcitol (Zemplar, Abbott Laboratories, IL, USA) 0,4 $\mu \mathrm{g} / \mathrm{kg} /$ three day of week and insulin,

(4) Aliskiren + Paricalcitol group (Group A+P) (n=8): Rats treated with ip paricalcitol 0,4 $\mu \mathrm{g} / \mathrm{kg} / \mathrm{three}$ day of week and aliskiren $10 \mathrm{mg} / \mathrm{kg} /$ day by oral gavage, and insulin,

(5) Control group (Group C) (n=8): Non diabetic rats without STZ treatment

All rats were killed by decapitation at 12 weeks after randomisation. Kidney, blood and urine samples were taken, serum was separated and aliquots were stored at at $-80^{\circ} \mathrm{C}$ until analysis.

\section{Evaluation of renal functions}

Serum and urinary creatinine were measured using commercially available clinical assay kits with an autoanalyzer (COBAS Integra 400 Plus, Roche Diagnostic, Rotkreuz, Switzerland) according to the manufacturers' instructions. The Creatinine clearance (CCr) was calculated using the following equation:

$\mathrm{CCr}$ (millilitersperminute per kilogram of body weight $)=$ [urinary $\mathrm{Cr}$ (milligrams per deciliter) X urinary volume (milliliters)/serum Cr (milligrams per deciliter)] X[1000/body weight (grams)]X[1/1440 (minutes)] [14].

Urinary albumin were measured with Immunoperoxidase assay (GenWayBiotech, San Diego, CA, ABD).

\section{Evaluation of lipid peroxidation/antioxidans in kidney}

Kidney tissue was homogenized in ice-cold $0.15 \mathrm{M} \mathrm{KCl}(10 \%, \mathrm{w} / \mathrm{v})$. Endogenous lipid peroxidation was assessed by measuring the levels of malondialdehyde (MDA) in tissue homogenates [15]. Tissue homogenates were mixed with sodium dodecyl sulfate, acetate buffer ( $\mathrm{Ph} \mathrm{3.5)}$ and aqueous solution of thio barbituric acid (TBA). After heating at $95^{\circ} \mathrm{C}$ for $60 \mathrm{~min}$, thered pigment produced was extracted with n-butanol-pyridine mixture and estimated by measuring the absorbance at $532 \mathrm{~nm}$. The break down product of 1,1,3,3-tetra ethoxy propane was used as a standard. Samples and standards were treated with butylated hydroxy toluene $(0.02 \%$ final concentration) to protect from further oxidation. The MDA levels were measured in $\mathrm{nmol} / \mathrm{g}$ tissue.

Glutathion (GSH) levels were measured as described by Beutleret et al. [16]. This method is based upon the development of a relatively stable yellow color when 5,5-dithiobis-(2- nitrobenzoate) is added to sulfhydryl compounds. GSH levels were expressed as $\mu \mathrm{mol} / \mathrm{g}$ tissue.

Superoxide dismutase (SOD) and glutathion peroxidase (GSH-Px) activities were determined in post mitochondrial fraction of kidney tissues, which were separated by sequential centrifugation. Tissue homogenates were centrifuged at $600 \times \mathrm{g}$ for $10 \mathrm{~min}$ at $4{ }^{\circ} \mathrm{C}$ to remove crude fractions. Then, supernatants were centrifuged at $10,000 \times \mathrm{g}$ for $20 \mathrm{~min}$ to obtain the postmitochondrial fraction.

SOD activity was assayed by its ability to increase the effect of riboflavin-sensitized photooxidation of odianisidine [17]. GSH-Px activity was measured using the method of Lawrence and Burk with cumene hydroperoxide as substrate [18]. In this method, GSH-Px activity was coupled to the oxidation of NADPH by glutathione reductase and the oxidation of NADPH was followed spectrophotometrically at $340 \mathrm{~nm}$ at $37 \circ$ C. GSH activity was assayed by the spectrophotometric method using 1-chloro-2,4-dinitro benzene as the substrate [19]. Protein levels were determined in post mitochondrial fractions using bicinchoninic acid [20]. The SOD activity was measured and expressed as units per mg protein (u/mg protein) and GSH-Px was expressed as $\mathrm{nmol} / \mathrm{min} / \mathrm{mg}$. 


\section{Kidney \\ Blood Pressure Research}

Kidney Blood Press Res 2014;39:581-590

\begin{tabular}{l|l}
\hline DOI: $10.1159 / 000368471$ & (C) 2014 S. Karger AG, Basel
\end{tabular}

Published onIIne: December 15, 2014

www.karger.com/kbr

Eren et al.: Aliskiren and Paricalcitol on Experimental Diabetic Nephropathy Model

Real Time PCR for Renin, Renin receptor, Angiotensin and Angiotensin Type 1 receptor

$25 \mathrm{mg}$ of kidney tissue containing both cortex and medulla sections were put into RNA later RNA preserving reagent (QIAGEN, Germany). Total RNA was isolated by using Roche High Pure RNA Isolation kit (Roche Diagnostics, Switzerland). Isolations were performed according to manufacturer's instructions. Tissues were homogenized by using Magnetic Pellet Motor Pestle (Sigma, USA). Supernatants containing nucleic acids were taken into $1.5 \mathrm{ml}$ microcentrifuge tubes containing $200 \mu \mathrm{l}$ of $100 \%$ ethanol. Samples then were moved into the spin columns and centrifuged at $13000 \mathrm{xg}$ for 2 minutes. After washing, they were quantified in NanoDrop spectrophotometer (ThermoScientific, USA) before cDNA synthesis.

For single strand cDNA synthesis, Transcriptor High Fidelity cDNA Synthesis Kit (Roche, Switzerland) was used according to manufacturer's instructions. Quality of samples were evaluated in NanoDrop Spectrophotometer (ThermoScientific, USA).

Realtime PCR was done by using TaqMan Master Kit (Roche, Switzerland). Primers used in Real Time PCR were Angiotensin, Angiotensin Receptor 1a, Renin, Renin Receptor and $\beta$-Actin as internal control and were acquired from Roche as Realtime Ready Primers with an optimized annealing temperature of $60^{\circ} \mathrm{C}$. Roche Light Cycler 480 was used to acquire results with PCR conditions 10 minutes at $95^{\circ} \mathrm{C}, 95^{\circ} \mathrm{C}$ for $10 \mathrm{~s}-60^{\circ} \mathrm{C}$ for $30 \mathrm{~s}-72^{\circ} \mathrm{C}$ for $1 \mathrm{~s}$ for 45 cycles and $40^{\circ} \mathrm{C}$ for $30 \mathrm{~s}$. All samples were done in triplets and results were analyzed on Light Cycler 480 Analysis Program v5.0 by 2-ddCP relative quantification.

\section{Histological and morphometric evaluation}

Dissected kidneys were fixed overnight with $4 \%$ formaldehyde in PBS (pH 7.2), processed, embedded in paraffin according to standard protocols, and sectioned at $4 \mu \mathrm{m}$. Slides were stained with hematoxylin and eosin (H\&E) and Massone trichrome using standard histologic procedures. Glomerular sclerosis, interstitial fibrosis and tubulointerstitial damage were evaluated in a blinded fashion by an experienced pathologist. Glomerular sclerosis were graded semiquantitative in four grades: $0=$ normal glomerulus, $1+=$ sclerosis involving less than $25 \%$ of glomerular surface area, $2+=$ sclerosis involving 25 to $50 \%, 3+=$ sclerosis involving more than $50 \%$ of glomerular surface area. Tubulointerstitial damage (tubulointerstitial inflammation, tubular injury, and interstitial fibrosis) was also scored semiquantitative as described previously : $0=$ normal interstitium and tubules; $1+=$ minimal injury $(<25 \%$ of tissue section affected $)$; $2+=$ mild injury ( 25 to $<50 \%$ of tissue section affected); $3+=$ moderate injury ( 50 to $75 \%$ of tissue section affected); and $4+=$ severe injury ( $>75 \%$ of tissue section involved).

Histomorphometric analysis was performed on a Masson's Trichrome stained slide at 100x magnification. For each case ten microscopic fields were randomly selected. interstitial fibrosis volume was quantified using an Olympus BX 51 with a DP2-BSW Soft Imaging System (Olympus Co., Hamburg, Germany) and expressed at $\mu \mathrm{m}^{2}$.

\section{Statistical analysis}

Data are presented as mean \pm SD. ANOVA and Bonferroni's tests were used to compare the means of continuous variables that were normally distributed and had equal variances. Welch and Games-Howel tests were used to compare the means of continuous variables that were normally distributed and did not have equal variances. The Kruskal-Wallis and Mann Whitney-U tests were used to compare the medians of non-normally distributed continuous variables. Two-tailed p-values $<0.05$ were considered statistically significant. Statistical analyses were performed using SPSS version 19.0 (SPSS Inc., Chicago, Ill., USA)

\section{Results}

\section{Renal function parameters}

Table 1 shows the renal function parameters in the 5 treatment groups. Twenty-four hour $\mathrm{CCr}$ did not differ in the $\mathrm{C}, \mathrm{A}, \mathrm{P}$, and $\mathrm{A}+\mathrm{P}$ groups. As expected, $\mathrm{CCr}$ decreased significantly in group D when compared to control animals $(\mathrm{p}<0.005)$. $\mathrm{CCr}$ was significantly higher in group $A+P$ than in group $D(p=0.026)$, but no differences were seen in group $A+P$ when compared to control rats ( $p>0.05)$. The mean albümin-to-creatinine ratio (ACR) did not differ in the $\mathrm{C}, \mathrm{A}, \mathrm{P}$, and $\mathrm{A}+\mathrm{P}$ groups. ACR was significantly higher in group $\mathrm{D}$ than in controls 


\section{Kidney Blood Pressure Research}

Table 1. Renal function parameters in 5 treatment groups

\begin{tabular}{|c|c|c|c|c|c|c|c|}
\hline Renal characteristics & $\begin{array}{l}\text { Group C } \\
\text { (Control) }\end{array}$ & $\begin{array}{l}\text { Group D } \\
\text { (Diabetes) }\end{array}$ & $\begin{array}{c}\text { Group A } \\
\text { (Aliskiren) }\end{array}$ & $\begin{array}{c}\text { Group P } \\
\text { (Paricalcitol) }\end{array}$ & $\begin{array}{c}\text { Group A+P } \\
\text { (Aliskiren+ } \\
\text { Paricalcitol) }\end{array}$ & $\mathrm{p}$ & $\mathrm{p}^{*}$ \\
\hline & $(n=8)$ & $(n=8)$ & $(n=8)$ & $(n=8)$ & $(n=8)$ & & \\
\hline $\begin{array}{l}\text { Creatinine Clearance } \\
(\mathrm{CCr})(\mathrm{ml} / \mathrm{min} / \mathrm{mg})\end{array}$ & $\begin{array}{c}7.35 \pm \\
1.08\end{array}$ & $\begin{array}{c}4.85 \pm \\
0.85\end{array}$ & $\begin{array}{c}6.15 \pm \\
0.75\end{array}$ & $\begin{array}{c}7.21 \pm \\
0.71\end{array}$ & $\begin{array}{c}9.90 \pm \\
2.90\end{array}$ & $<0.005$ & 0.026 \\
\hline $\begin{array}{l}\text { Albumin-to-creatinine } \\
\text { ratio }(A C R)(\mu \mathrm{g} / \mathrm{mg})\end{array}$ & $\begin{array}{c}580.65 \pm \\
235.31\end{array}$ & $\begin{array}{c}1823.95 \pm \\
1102.04\end{array}$ & $\begin{array}{c}799.22 \pm \\
212.84\end{array}$ & $\begin{array}{c}1083.82 \pm \\
761.68\end{array}$ & $\begin{array}{c}662.87 \pm \\
286.69\end{array}$ & $<0.005$ & 0.004 \\
\hline $\begin{array}{l}\text { Kidney-to-body } \\
\text { weight ratio (mg/g) }\end{array}$ & $\begin{array}{c}3.10 \pm \\
0.05 \\
\end{array}$ & $\begin{array}{c}5.00 \pm \\
1.14 \\
\end{array}$ & $\begin{array}{c}3.84 \pm \\
0.49 \\
\end{array}$ & $\begin{array}{c}3.62 \pm \\
0.28 \\
\end{array}$ & $\begin{array}{c}3.47 \pm \\
0.44 \\
\end{array}$ & $<0.005$ & 0.01 \\
\hline
\end{tabular}

$(p<0.005)$. On the other hand, this parameter was significantly lower in group A+P than in group D $(p=0.004)$. Furthermore, combination therapy significantly increased CCr (Group $\mathrm{A}+\mathrm{P}$ vs Group A, $\mathrm{p}<0.005$; Group A+P vs Group P, $\mathrm{p}=0.022$ ) and reduced ACR (Group A+P vs Group A, p=0.018; Group A+P vs Group P, $p<0.005$ ) when compared to monotherapy.

\section{Oxidative stress parameters}

Levels of the kidney MDA did not differ in the C, A, P, and A+P groups. Kidney MDA levels were significantly increased in Group D when compared to controls $(p<0.005)$ indicating an excess lipid peroxidation in DN. This parameter was significantly lower in group $A+P$ than in group $D(p=0.004)$, but no differences were seen in group $A+P$ when compared to control rats $(p>0.05)$. Similarly, tissue level of GSH ( $p<0.005), G S H-P x(p<0.005)$ and SOD $(p<0.005)$ kidney tissue activities were decreased in Group D when compared to control group. Level of GSH ( $p=0.003)$, GSH-Px $(p=0.004)$ and SOD $(p<0.005)$ activities were significantly higher in group $A+P$ than in group $D$. There were no significant differences of these parameters in Group A+P when compared to controls ( $p>0.05$ ) (figure 1).

\section{Renal mRNA expression of RAS parameters}

Expression of Renin, Renin receptor, Angiotensin II and Angiotensin Type 1 receptor mRNA did not differ in the $C, A, P$, and $A+P$ groups. Expression of renin $(p<0.005)$, renin receptor $(p<0.005)$, angiotensin II ( $p=0.001)$, and angiotensin II type 1 receptor $(p=0.002)$ were significantly increased in group $\mathrm{D}$ when compared to controls. Expression of renin $(\mathrm{p}<0.005)$, angiotensin II $(\mathrm{p}=0.012)$, and angiotensin type 1 receptor $(\mathrm{p}=0.018)$ were significantly lower in group $A+P$ than in group $D$. However, there were no significant differences of these parameters in Group $A+P$ when compared to controls $(p>0.05)$ (figure 2).

\section{Histological and morphometric evaluation}

Histological analysis. The histological findings in the 5 treatment groups are reported in table 2. Tubulointerstitial inflammation $(\mathrm{p}<0.005)$, tubular injury $(\mathrm{p}<0.005)$ and interstitial fibrosis $(p<0.005)$ parameters were significantly difference between control and diabetic groups. Tubulointerstitial inflammation $(p=0.004)$, tubular injury $(p=0.013)$ and interstitial fibrosis $(p=0.003)$ parameters were significantly lower in group $A+P$ than in group $D$. However, there were no significant differences of these parameters in Group A+P when compared to controls ( $p>0.05$, respectively). Combination therapy did not improve renal histology (tubulointerstitial inflammation, tubular injury, interstitial fibrosis) (Group A+P vs Group A, p>0.05, respectively; Group A+P vs Group P, p>0.05, respectively) when compared to monotherapy.

Histomorphometric analysis for interstitial fibrosis volume. Interstitial fibrosis volume was significantly increased in group D when compared to controls $(\mathrm{p}<0.005)$. Interstitial fibrosis volume was significantly lower in group $A+P$ than in group $D(p<0.005)$, but 


\section{Kidney \\ Blood Pressure Research}

Table 2. Histology findings in the 5 treatment groups

\begin{tabular}{lccccccc}
\hline & $\begin{array}{c}\text { Group C } \\
\text { (Control) }\end{array}$ & $\begin{array}{c}\text { Group D } \\
\text { (Diabetes) }\end{array}$ & $\begin{array}{c}\text { Group A } \\
\text { (Aliskiren) }\end{array}$ & $\begin{array}{c}\text { Group P } \\
\text { (Paricalcitol) }\end{array}$ & $\begin{array}{c}\text { Group A+P } \\
\text { (Aliskiren+ } \\
\text { Paricalcitol) }\end{array}$ & $\mathrm{p}$ & $\mathrm{p}^{*}$ \\
\hline Tubulointerstitial & $0.25 \pm 0.46$ & $2.52 \pm 0.68$ & $0.34 \pm 0.54$ & $0.28 \pm 0.34$ & $0.98 \pm 0.52$ & $<0.005$ & 0.004 \\
Inflammation & & & & & & & \\
Tubular injury & $0.14 \pm 0.32$ & $2.75 \pm 0.46$ & $0.42 \pm 0.18$ & $0.37 \pm 0.26$ & $1.01 \pm 0.84$ & $<0.005$ & 0.013 \\
Interstitial fibrosis & $0.22 \pm 0.18$ & $2.87 \pm 0.68$ & $0.38 \pm 0.54$ & $0.36 \pm 0.30$ & $0.86 \pm 0.64$ & $<0.005$ & 0.003 \\
\hline \multicolumn{7}{l}{ Data is presented as mean \pm SD. p: group D vs group C, $\mathrm{p}^{*}$ : group D vs group A+P } \\
\hline
\end{tabular}

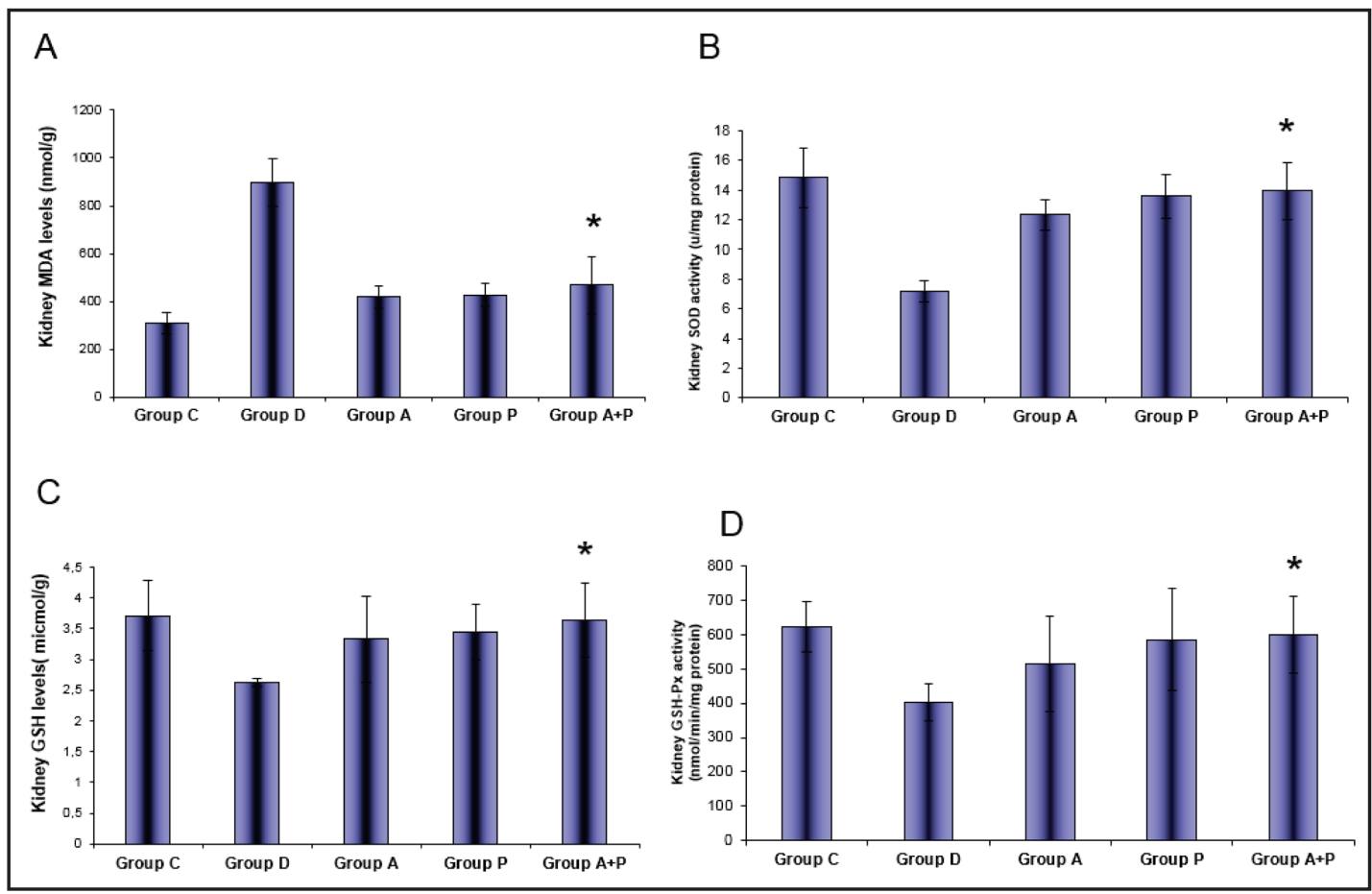

Fig. 1. Changes in renal tissue MDA (A), SOD (B), GSH (C), GSH-Px (D) levels and activities in 5 treatment groups. MDA: malondialdehyde; SOD: superoxide dismutase; GSH: glutathion; GSH-Px: glutathion peroxidase. Group D: Diabetic nephropathy; Group A: Aliskiren; Group P: Paricalcitol; Group A+P: Aliskiren + Paricalcitol; Group C: Control. *: p=0.004 (A), p<0.005 (B), p=0.003 (C), p=0.004 (D) (p: Group A+P vs Group D).

no difference was seen in group $\mathrm{A}+\mathrm{P}$ when compared to control rats ( $\mathrm{p}>0.05$ ) (figure 3 ). Furthermore, combination therapy significantly decreased interstitial fibrosis volume when compared to monotherapy (Group A+P vs Group A, p<0.005; Group A+P vs Group P, p=0.002).

\section{Discussion}

The present experimental study demonstrated for the first time that aliskiren and paricalcitol combination treatment might reduce progression of diabetic nephropathy by improving renal interstitial fibrosis on DN model in rats. Combination therapy improved renal functions, intrarenal anti-oxidant enzyme activities, decreased intrarenal RAAS activity, and lowered interstitial fibrosis volume. 


\section{Kidney

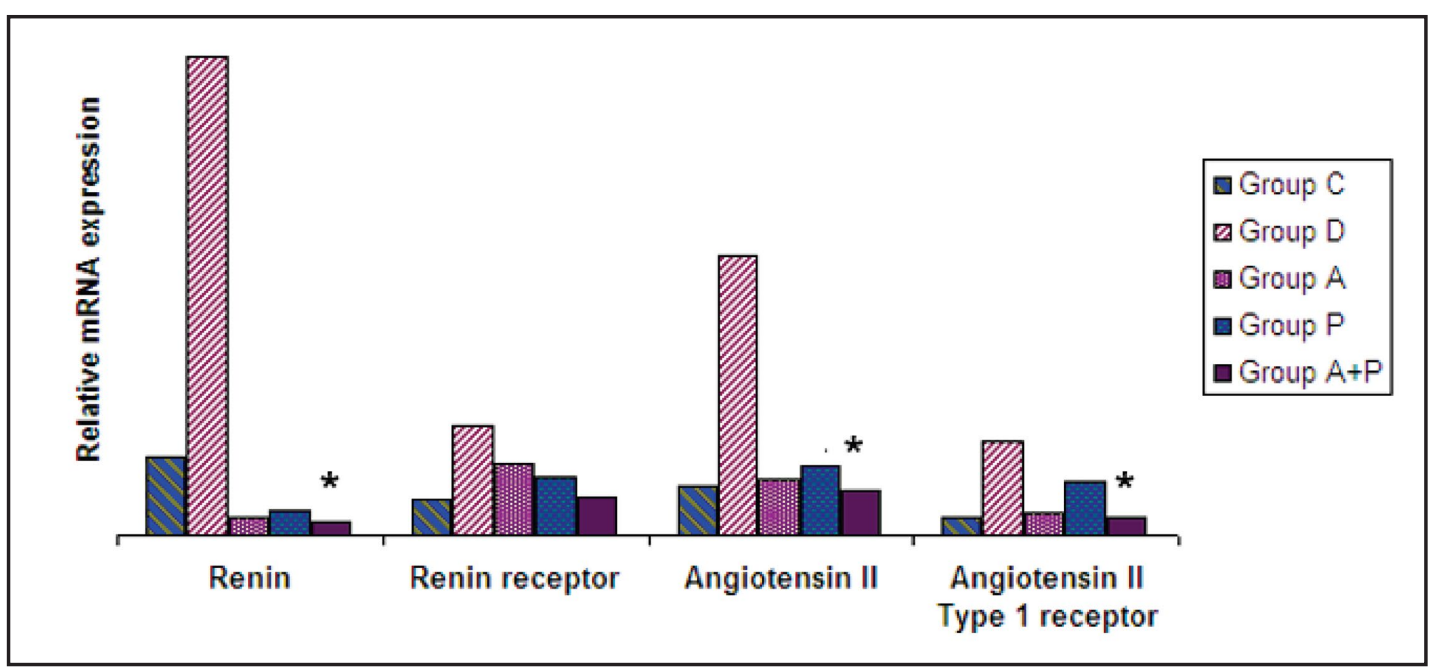

Fig. 2. Renal mRNA expression of RAAS parameters in 5 treatment groups. Group D: Diabetic nephropathy; Group A: Aliskiren; Group P: Paricalcitol; Group A+P: Aliskiren + Paricalcitol; Group C: Control. *: p<0.005 (renin) (Group A+P vs Group D), p=0.012 (angiotensin II) (Group A+P vs Group D), p=0.018 (angiotensin II type I receptor) (Group A+P vs Group D).

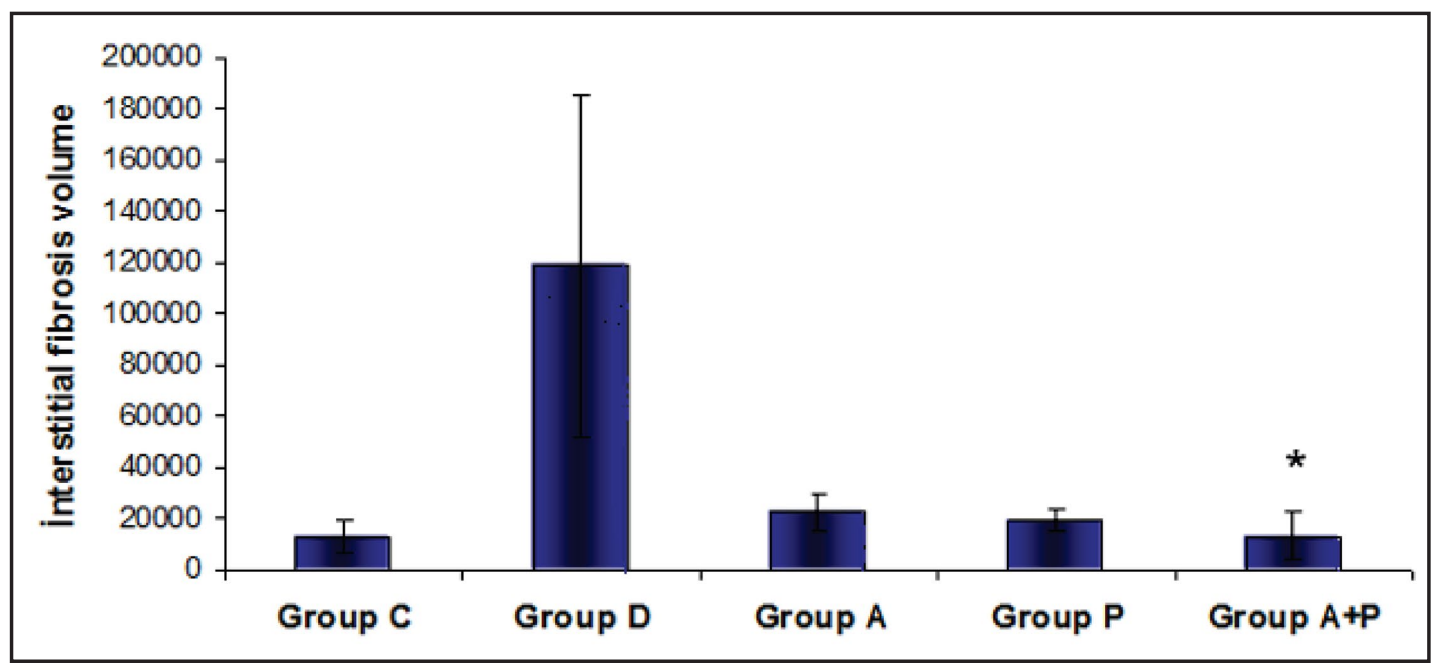

Fig. 3. Histomorphometric analysis for fibrosis volume in 5 treatment groups. Group D: Diabetic nephropathy; Group A: Aliskiren; Group P: Paricalcitol; Group A+P: Aliskiren + Paricalcitol; Group C: Control . * p $<0.005$ (Group A+P vs Group D).

It is well known that the RAAS pathway is activated in the diabetic kidney. The renoprotective effects of the RAAS-inhibiting drugs have been shown to involve the normalization of glomerular hyperperfusion and hyperfiltration, restoration of glomerular barrier function, and a reduction of the non-hemodynamic effects of angiotensin II and aldosterone [21].

We demonstrated that aliskiren and paricalcitol combination treatment reduced renal mRNA expression of renin, angiotensin II and angiotensin II type 1 receptors in rats. We interpreted that optimal suppression of RAAS activity via combination treatment may inhibit compensatory increase in renin and angiotensin II levels. Feldman et al showed that aliskiren prevents the development of albuminuria, fibrosis and glomerulosclerosis on DN model in rats by suppression of intrarenal RAAS [22]. We also demonstrated that aliskiren or 


\section{Kidney Blood Pressure Research} \begin{tabular}{l}
\hline Kidney Blood Press Res 2014;39:581-590 \\
\begin{tabular}{l|l}
\hline DOI: 10.1159/000368471 \\
Publisned onllne: December 15, 2014
\end{tabular} \\
\hline $\begin{array}{l}\text { o 2014 S. Karger AG, Basel } \\
\text { www.karger.com/kbr }\end{array}$
\end{tabular}

Publisned onine: December 15, 2014

Eren et al.: Aliskiren and Paricalcitol on Experimental Diabetic Nephropathy Model

paricalcitol alone moderately reduced interstitial fibrosis in diabetic rats; interestingly, they appeared to act synergistically, and their combination completely blocked the development of interstitial fibrosis. We speculated that combination therapy may contribute to renal protection by reducing the deleterious effects of angiotensin II and aldosterone more effectively.

However, our data is particularly different from the following literature. Fraune et al demonstrated that aliskiren plus losartan increased plasma and renal renin expression [23]. According to our results, aliskiren and combination treatment decreased renal renin expression. The finding that 1,25(OH)2D3 represses renin gene transcription [24, 25] provides a good basis to use paricalcitol for the suppression of the compensatory renin increase because vitamin $\mathrm{D}$ analogs directly inhibit renin biosynthesis. Furthermore, aliskiren has been shown to reduce the renal expression of the pro-renin receptor in an animal model of diabetes [22]. Based on these findings, it can be speculated that combination treatment could have exerted their beneficial effects in the prevention of interstitial fibrosis through RAAS at every step. We interpreted that aliskiren and renal renin and pro-renin expression is a potential pathophysiological dilemma in the setting of DN, future studies are needed to shed more light on this issue.

As we all know, the structural/cellular basis is easily destroyed by the oxidative stress which has been verified to participate in the pathogenesis of DN [26]. Oxidative stress refers to the imbalance between the antioxidative defense system and the oxidative system [26, 27]. Recently, it is documented that paricalcitol has not only renin inhibitor effects, but also antioxidant effects [12, 28-30]. Izquierdo et al. reported that paricalcitol decreases serum MDA levels and increases serum GSH, thioredoxin, catalase and SOD activities in hemodialysis patients [29]. Similarly, Husain et al reported that paricalcitol and enalapril combination treatment inhibits the increase in cardiac MDA levels and reduces cardiac SOD activity in uremic rats [12]. In the present study, the activity of SOD and level of GSH in glomeruli of diabetic rats were evidently inhibited along with a distinct increase in MDA level. By contrast, following aliskiren and paricalcitol combination treatment, the activity of all the enzymes displayed a significant increase accompanied with the obvious decrease in MDA level. These results demonstrate that combination treatment possesses antioxidant activity and could improve the antioxidative defense system of the diabetic kidney.

This is the first demonstration that paricalcitol can be used to block the compensatory renin increase and intrarenal oxidative stress in a combination therapy with aliskiren. The results of the present study seem to suggest that combination treatment may have benefits in renal functions. However, histological parameters did not improve significantly. Therefore, it is likely that the observed effects of aliskiren and paricalcitol in the treatment of DN could mainly exerted through anti-oxidant and anti-angiotensin mechanisms.

\section{Conclusion}

Several caveats of this report merit comment. The lack of hemodynamic measurement is an obvious limitation. Altough this is an experimental study of DN treatment in the rat, our report provides a proof of concept and could have implications for further clinical research in human. Another important limitation is that we did not attemp to measure renal pro-renin expression in the rats.

These limitations notwithstanding, we demonstrate for the first time that administration of aliskiren and paricalcitol improves renal function parameters, RAAS activity and antioxidant enzymes in a rat model of DN. While aliskiren and paricalcitol combination treatment may have a role in DN, further animal and clinical studies are needed before any definite conclusion can be drawn. 


\section{Kidney \\ Blood Pressure Research}

Eren et al.: Aliskiren and Paricalcitol on Experimental Diabetic Nephropathy Model

\section{Disclosure Statement}

The authors of this manuscript state that they do not have any conflict of interests and nothing to disclose.

\section{Acknowledgements}

This work was supported by The Scientific and Technical Research Council of Turkey (TUBITAKTUBITAK SBAG 111S299). The authors would like to acknowledge the contributions of Prof. Dr. Müjdat Uysal. We thank Burak Çağlayan and Mustafa Çağlar Beker for expert technical assistance.

\section{References}

1 Reutens AT, Atkins RC: Epidemiology of diabetic nephropathy. Contrib Nephrol 2011;170:1-7.

$\checkmark 2$ Ritz E, Rychlík I, Locatelli F, Halimi S: End-stage renal failure in type 2 diabetes: A medical catastrophe of worldwide dimensions. Am J Kidney Dis 1999;34:795-808.

-3 Schmieder RE, Bakris G, Weir MR: Telmisartan in incipient and overt diabetic renal disease. J Nephrol 2011;24:263-273.

4 Anderson S, Komers R: Inhibition of the renin-angiotensin system: is more better? Kidney Int 2009;75:1214.

5 Barrios V, Escobar C: Aliskiren in the management of hypertension. Am J Cardiovasc Drugs 2010;10:349358.

6 Riccioni G: Aliskiren in the treatment of hypertension and organ damage. Cardiovasc Ther 2011;29:77-87.

7 Drueke TB: Which vitamin D derivative to prescribe for renal patients. Curr Opin Nephrol Hypertens 2005;14:343-349.

8 Zhang Z, Zhang Y, Ning G, Deb DK, Kong J, Li YC: Combination therapy with AT1 blocker and vitamin D analog markedly ameliorates diabetic nephropathy: blockade of compensatory renin increase. Proc Natl Acad Sci USA 2008;105:15896-91501.

-9 Tan X, Li Y, Liu Y: Paricalcitol attenuates renal interstitial fibrosis in obstructive nephropathy. J Am Soc Nephrol 2006;17:3382-3393.

10 Mizobuchi M, Morrisey J, Finch JL, Martin DR, Liapis H, Akizawa T, Slatopolsky E: Combination therapy with an angiotensin converting enzyme inhibitor and a vitamin D analog suppresses the progression of renal insufficiency in uremic rats. J Am Soc Nephrol 2007;18:1796-1806.

-11 De Zeeuw D, Agarwal R, Amdahl M, Audhya P, Coyne D, Garimella T, Parving HH, Pritchett Y, Remuzzi G, Ritz E, Andress D: Selective vitamin D receptor activation with paricalcitol for reduction of albuminuria in patients with type 2 diabetes (VITAL study): a randomised controlled trial. Lancet 2010;376:543-1551.

12 Husain K, Ferder L, Mizobuchi M, Finch J, Slatopolsky E: Combination therapy with paricalcitol and enalapril ameliorates cardiac oxidative injury in uremic rats. Am J Nephrol 2009;29:465-472.

13 Freundlich M, Quiroz Y, Zhang Z, Zhang Y, Bravo Y, Weisinger JR, Li YC, Rodriguez-Itube B: Suppression of renin-angiotensin gene expression in the kidney by paricalcitol. Kidney Int 2008;74:1394-1402.

14 Kitada M, Takeda A, Nagai T, Ito H, Kanasaki K, Koya D: Dietary restriction ameliorates diabetic nephropathy through anti-inflammatory effects and regulation of the autophagy via restoration of Sirt1 in diabetic Wistar fatty (fa/fa) rats: a model of type 2 diabetes. Exp Diabetes Res 2011;9081-9085.

15 Ohkawa H, Ohishi N, Yagi K: Assay for lipid peroxidation in animal tissues by thiobarbituric acid reaction. Anal Biochem 1979;95:351-358.

16 Beutler E, Duron O, Kelly BM: Improved method for the determination of blood glutathione. J Lab Clin Med 1979;61:882-888.

17 Mylorie AA, Collins H, Umbles C, Kyle J: Erythrocyte superoxide dismutase activity and other parameters of copper status in rats ingesting lead acetate. Toxicol Appl Pharmacol 1986;82:512-520. 


\section{Kidney \\ Blood Pressure Research}

18 Lawrence RA, Burk RF: Glutathione peroxidase activity in seleniumdeficient rat liver. Biochem Biophys Res Commun 1976;71:952-958.

19 Habig WH, Jacoby WB: Assays for differentation of glutathione stransferases. Methods Enzymol 1981;77:398-405.

-20 Smith PK, Krohn RI, Hermanson GT, Mallia AK, Gartner FH, Provenzano MD, Fujimoto EK, Goeke NM, Olson BJ, Klenk DC: Measurement of protein using bicinchoninic acid. Anal Biochem 1985;150:76-85.

-21 Tylicki L, Lizakowski B: Renin-angiotensin-aldosterone system blockade for nephroprotection: current evidence and future directions. J Nephrol 2012;25:900-910.

-22 Feldman DL, Jin L, Xuan H, Contrepas A, Zhou Y, Webb RL, Mueller DN, Feldt S, Cumin F, Maniara W, Persohn E, Schuetz H, Jan Danser AH, Nguyen G: Effects of aliskiren on blood pressure, albuminuria, and (pro)renin receptor expression in diabetic TG(mRen-2)27 rats. Hypertension 2008;52:130-136.

-23 Fraune C, Lange S, Krebs C, Hölzel A, Baucke J, Divac N, Schwedhelm E, Streichert T, Velden J, Garrelds IM, Danser AH, Frenay AR, van Goor H, Jankowski V, Stahl R, Nguyen G, Wenzel UO: AT1 antagonism and renin inhibition in mice: pivotal role of targeting angiotensin II in chronic kidney disease. Am J Physiol Renal Physiol 2012;303:F1037-1048.

24 Yuan W, Pan W, Kong J, Zheng W, Szeto FL, Wong KE, Cohen R, Klopot A, Zhang Z, Li YC: 1,25-Dihydroxyvitamin D3 suppresses renin gene transcription by blocking the activity of the cyclic AMP response element in the renin gene promoter. J Biol Chem 2007;282:29821-29830.

25 Li YC, Kong J, Wei M, Chen ZF, Liu SQ Cao LP: 1,25-Dihydroxyvitamin D(3) is a negative endocrine regulator of the renin-angiotensin system. J Clin Invest 2002;110:229-238.

26 Aydin A, Orhan H, Sayal A, Özata M, Şahin G, Iş̦mer A: Oxidative stress and nitric oxide related parameters in type II diabetes mellitus: effects of glycemic control. Clin Biochem 2001;34:65-70.

27 Chauhan V, Chauhan A: Oxidative stress in Alzheimer's disease. Pathophysiol 2006;13:195-208.

-28 Ari E, Kedrah AE, Alahdab Y, Bulut G, Eren Z, Baytekin O, Odabasi D: Antioxidant and renoprotective effects of paricalcitol on experimental contrast-induced nephropathy model. Br J Radiol 2012;85:1038-1043.

29 Izquierdo MJ, Cavia M, Muniz P, De Francisco AL, Arias M, Santos J, Abaigar P: Paricalcitol reduced oxidative stress and inflammation in hemodialysis patients. BMC Nephrol 2012;13:159.

30 Gonzalez-Parra E, Rojas-Rivera J, Tunon J, Praga M, Ortiz A, Egido J: Vitamin D receptor activation and cardiovascular disease. Nephrol Dial Transplant 2012;27:IV17-21. 